\title{
Intercultural Wonderment and Study Abroad
}

\author{
Mark E. Engberg \\ Loyola University Chicago \\ T.J. Jourian \\ Loyola University Chicago
}

\section{Intercultural Wonderment and Study Abroad}

Although many findings related to study abroad point to the myriad benefits of such experiences, these studies focus more exclusively on direct effects (Engberg, 2013; Vande Berg, Connor-Linton, \& Paige, 2009), overlooking a number of process-oriented variables that mediate the development of different outcomes associated with study abroad (Pascarella \& Terenzini, 2005). Further, more recent publications have questioned whether study abroad experiences are ubiquitous in their benefits to all students (Salisbury, An, \& Pascarella, 2013; Twombly, Salisbury, Tumanut, \& Klute, 2012), suggesting a more nuanced approach is needed in identifying which aspects of the study abroad experience (e.g., program design, pedagogy, interactions with the host country) are most influential in predicting student learning and developmental outcomes. In this study, we introduce and examine the role of intercultural wonderment in fostering students' development of a global perspective during a one semester study abroad experience. Intercultural wonderment encapsulates the underlying curiosity in individuals to seek out new and different experiences while studying abroad and involves a willingness and capacity to deal with discomfort and disequilibrium.

\section{Purpose and Significance of Study}

The rapid emulation and expansion of study abroad programs has necessitated an increased campus commitment to understanding the broader mechanisms that foster global learning and development. Researchers, for, instance, have stressed the importance of moving assessment of study abroad from a more general understanding (i.e., an understanding mainly of direct or correlational effects) to one that aims to specifically connect program-related design elements and processes to student outcomes (Engberg, 2013). Through an exhaustive literature review and extensive input from study abroad practitioners, we developed a study abroad survey that more purposefully examines the quality of the study abroad experience, including the developmental influence of faculty and staff; the experiences of students both inside and outside the classroom; and students' level of exploration, immersion, and interaction with the host country. Exploring these influences is essential in understanding why study abroad works, as well as what optimizes the learning potential within an immersion experience. Thus, this study seeks to identify and explore aspects of a study abroad experience that foster participants' intercultural wonderment as well as how intercultural wonderment influences students' development of a global perspective. 


\section{Intercultural Wonderment}

Intercultural wonderment is manifested as students intentionally push themselves outside their comfort zones, feel immersed in the culture of the host country, explore new habits and behaviors while abroad, and interact with individuals from the host country outside the classroom. By engaging in unfamiliar environments and experiencing differing values, students encounter "provocative moments" (Pizzolato, 2005, p. 629) that trigger the disequilibrium needed to develop their "capacity to define [their] beliefs, identity, and social relations" and achieve self-authorship (Baxter Magolda, 2008, p. 269). Piaget (1985) further posits that the process whereby individuals assimilate discrepant or foreign information into a particular cognitive schema can foster the type of disequilibrium necessary to enlarge and recalibrate an underlying cognitive structure. Moreover, Kegan (1994) suggests that students' ability to "construct meaning" (p. 199) in more developmentally complex ways requires periods of stability and instability that forces them to continuously reconstruct their relationships with their surrounding environment. Thus, intercultural wonderment encapsulates a number of "provocative moments" in which students are intentionally moving outside their comfort zones and exploring new relationships, contexts, values, and perspectives that concomitantly stimulate growth and development.

Encountering situations that arouse internal contradictions in moral and intellectual reasoning challenges students to develop new ideas and reactivate modes of thought that had become routinized, automatic, and unconscious, a process Langer (1978) refers to as "mindlessness." Encapsulating this notion of active thinking, Lewis et al. (2010) describe the concept of "mindful wonderment" as "a way to maintain open wonder and curiosity about possibilities for seeing, hearing and even responding to others from a fresh perspective" (p. 83). Similarly, Gurin et al. (2002) posit that students' encounters with difference are important catalysts in triggering more deliberate and active forms of thinking and learning. Multicultural experiences that highlight "encountering two cultures simultaneously" (Cheng, Leung, \& Wu, 2011, p. 814), can enhance creativity by challenging conformity to one's own cultural norms and ideas (Leung \& Chiu, 2010). This process is amplified by one's openness to these encounters (Leung \& Chiu, 2008), suggesting that a level of personal investment or motivation is necessary to purposefully engage novel environments in ways that are consistent with students' personal learning goals and the meaning they derive from their engagement (Braskamp, 2009; Maehr \& Braskamp, 1986).

When active experimentation, mindfulness, and personal investment are steeped within an intercultural context, students develop a greater capacity toward intercultural wonderment which, in turn, can foster global citizenship and intercultural outcomes. Nussbaum (1997), for instance, describes how encountering "both sameness and difference" (p. 95) prepares students for world citizenship through the development of three sets of capacities: (i) critical thinking and critical selfexamination, (ii) seeing one's connection to others, and (iii) empathy through narrative imagination, i.e. placing one's self in another's circumstance. Similarly, the Association of American Colleges and Universities' (2007) suggests that intercultural competence is achieved through deliberate 


\section{Mark E. Engberg \& T.J. Jourian}

experimentation and engagement with diverse communities. As such, we situate intercultural wonderment as an important mediator of global learning and developmental outcomes that expand across cognitive, interpersonal, and intrapersonal dimensions of student development.

\section{The Study Abroad Context}

The new cultural context experienced during study abroad provides students an opportunity to reflect on their home culture as well as the host culture; however, merely sending students abroad without a variety of intentionally designed interventions is insufficient in reaching the myriad outcomes noted in the study abroad literature. Much of this literature focuses on the significance of intentionally designing and facilitating activities inside and outside of the classroom (Jessup-Anger, 2008; Jones, Rowan-Kenyone, Ireland, \& Niehaus, 2012; Knight \& Schmidt-Rinehart, 2010; Lee, 2012; Savicki \& Cooley, 2011; Vande Berg, et al., 2009). In accordance with this contention, the review that follows examines the pre- and post-departure context, curricular context, co-curricular and community-based context, and the role of faculty and staff in facilitating student learning and development.

\section{Pre-Post Departure Characteristics}

Pre-departure experiences with the home campus are important considerations in understanding students' readiness to engage in a study abroad experience, particularly their level of engagement with the campus co-curriculum and opportunities to explore and/or interact with diverse others (Braskamp and Engbert, 2011; Twombly, et al., 2012). Braskamp and Engbert (2011) found that students who had positive perceptions of their campus community were associated with higher levels of global perspective-taking, although the institutional type (e.g. selective institutions, religiouslyaffiliated) can partially mitigate this relationship. In addition to campus-based experiences, students' exposure to pre-departure orientations can be beneficial, particularly when a cultural component is integrated into the experience and in short-term programs when students have less time to acclimate to a new culture (Rexeisen \& Al-Khatib, 2009; Vande Berg et al., 2009). Finally, both re-entry and post-departure reflection help students make meaning of their experiences in the context of their home campus and beyond, while easing the adjustment to their home or campus communities (Jones, et al, 2012; Rexeisen \& Al-Khatib, 2009; Wielkiewicz \& Turkowski, 2010).

\section{Curricular Context}

Literature on the study abroad curriculum includes attention to its pedagogy (Coryell, 2011; Marx \& Moss, 2011), whether the formal curriculum supports holistic and intercultural student development (Jessup-Anger, 2008), and the use of blogs, other online forums, and reflective activities and journals as curricular tools (Jessup-Anger, 2008; Lee, 2012; Savicki \& Cooley, 2011). Experiential activities, such as fieldwork and service that include opportunities for students to interact

and speak with the host country, and classroom-based reflective activities are essential in optimizing the benefits of the study abroad experience (Braskamp and Engberg, 2011; Jessup-Anger, 2008; Kolb, 1984; Lee, 2012; Savicki \& Cooley, 2011; Vande Berg et al., 2009). The academic context abroad 
(e.g., whether students are in classes with just U.S. students, students from the host country, other non-U.S. international students, or some mixture of the above populations) also functions as a key element in how students learn and making meaning of their experiences (Jones, et al, 2012; Knight \& Schmidt-Rinehart, 2010; Vande Berg, et al, 2009). Language use is another important factor, both in instruction and contact with native speakers in the classroom (Knight \& Schmidt-Rinehart, 2010; Martinsen, 2011; Vande Berg et al., 2009). Finally, the incorporation of self-authorship opportunities that allow students to reflect and make-meaning of their experience (Baxter-Magolda, 2001; Kegan, 1994) are critical pedagogical features of effective study abroad courses.

\section{Co-curricular and Community Context}

Students' co-curricular involvement while studying abroad is also important to examine in understanding the full range of opportunities that may potentially impact the achievement of program outcomes. In particular, students' living arrangements (Martinsen, 2011; Vande Berg et al., 2009) and structured and unstructured excursions, trips, and experiential activities, such as service and fieldwork (Braskamp and Engberg, 2011; Vande Berg et al., 2009), are significant, out-of-class experiences. In both instance, it is important to examine the amount of time spent with native speakers (Martinsen, 2011) and students' opportunities to interact with diverse members of the host community (Coryell, 2011; Lee, 2012). Additionally and relatedly, the demographics of and interactions with other study abroad participants (Jones, et al, 2012; Knight \& Schmidt-Rinehart, 2010) influences outcomes related to transformative learning and the development of a global perspective.

\section{Developmental Influence of Faculty and Staff}

Faculty and staff play an influential role in facilitating student development through appropriate levels of challenge and support (Kuh, 2003; Sanford, 1966) and fostering critical reflection across students' various identities and understandings of the host culture (Jones, et al, 2012; Knight \& Schmidt-Rinehart, 2010). Faculty need to be accessible inside and outside of the classroom, show up authentically, deliberately make efforts to know their students, and effectively communicate with them in order to foster positive relationships with their students (Chickering \& Reisser, 1993). In order to optimize the learning experience, faculty should intentionally structure the nature and frequency of their out-of-classroom contact with students (Kuh, 2003), while also incorporating diverse perspectives in course assignments and facilitating class discussions around difference to further students' intellectual, interpersonal, and cultural competence (Chickering \& Reisser, 1993; Reisser, 1995). Faculty and staff can also maximize students' opportunities to reflect on both their home and host cultures by facilitating avenues for meaningful interactions and relationships with host families (e.g., through ethnographic and oral interviews; Jessup-Anger, 2008; Knight \& SchmidtRinehart, 2010), which can also enhance students' proficiency and understanding of sociolinguistic dimensions of the host country's language (Lee, 2012). Staff can also play an important coaching role in supporting students, while challenging them to make meaning of their experiences (Love \& Guthrie, 1999). 


\section{Conceptual Framework}

As shown in Figure 1, the study's conceptual framework is informed by the assertion that outcomes of a study abroad experience are influenced by the interaction of the pre-departure context (i.e., student background characteristics and experiences in the home campus; Astin, 1977), and the curricular, co-curricular, and community contexts that comprise a purposeful program of study designed to foster holistic student development (Braskamp, Trautvetter, \& Ward, 2006). The conceptual framework assumes that the study abroad program does not operate in a vacuum; rather, it is contextualized within the students' home campus and addresses factors related to students' access to study abroad and their perceptions of campus climate, as well as the institution's curricular and cocurricular opportunities to engage with diversity. Moreover, as students are not blank slates upon embarking on their study abroad journey, factors such as language proficiency, class standing, identity, motivations for studying abroad, and previous excursions are also accounted for in the model.

The study abroad experience is comprised of curricular, co-curricular, and community-based experiences. The level of immersion is mitigated through a number of intentional practices, including critical reflection, discourse with diverse others, and intentionally designed and skillfully facilitated interventions inside and outside of the classroom. When these elements come together in a structured and purposeful manner, they provide the fertile ground to challenge and support students in achieving greater levels of intercultural wonderment, which concomitantly fosters a host of global learning and developmental outcomes.

\section{Research Questions}

Based on the conceptual framework above, we explore three research questions in the study:

1. What are the pre-posttest differences in students' global perspective scores during a one semester study abroad experience?

2. What is the relationship between intercultural wonderment and students' development of a global perspective, controlling for background, pre-departure, and study abroad curricular, co-curricular, and community experiences, during a one semester study abroad experience?

3. What is the relationship between students' background, pre-departure, and study abroad curricular, co-curricular, and community experiences and their level of intercultural wonderment, during a one semester study abroad experience? 
Figure 1. Conceptual Framework for the Study
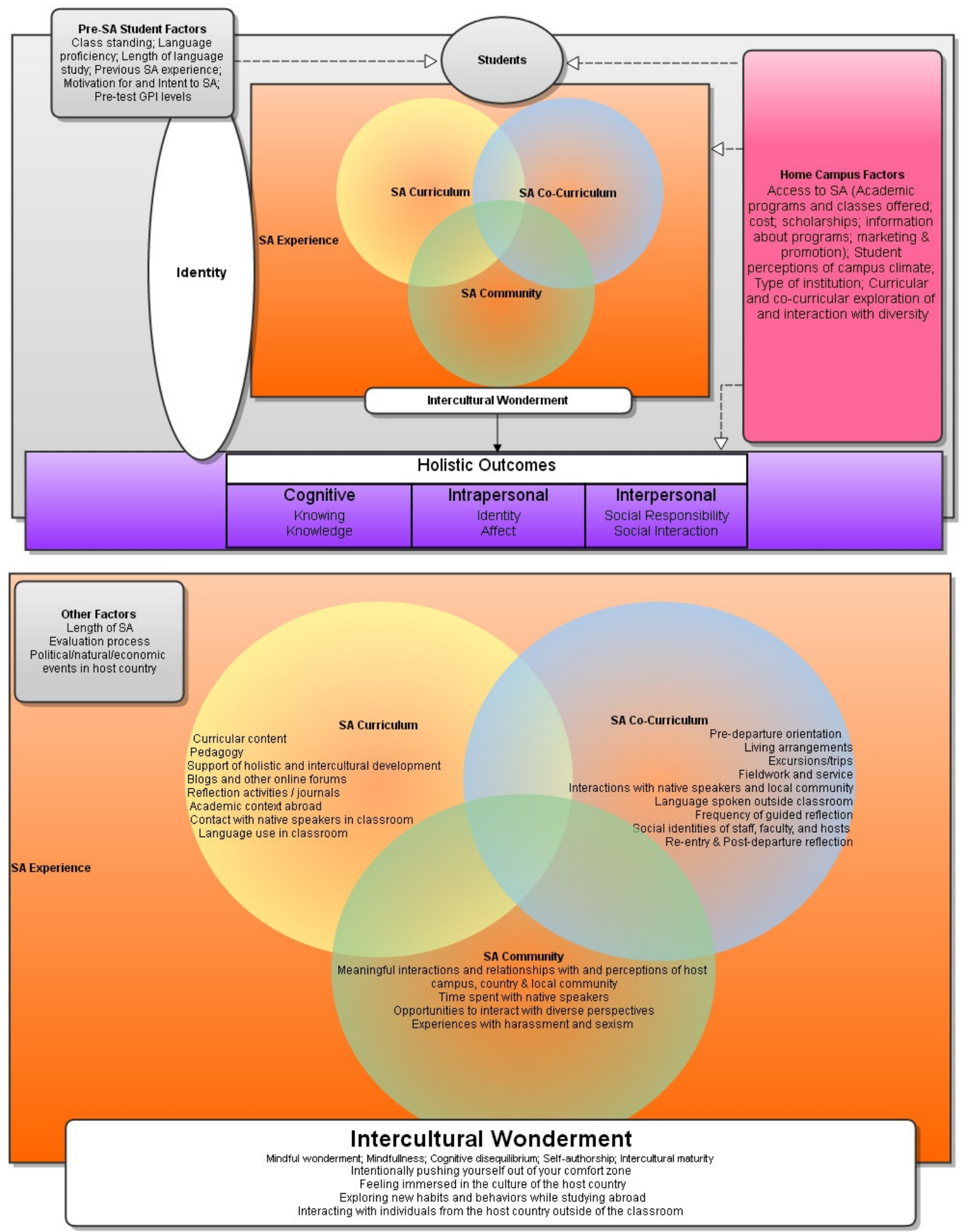


\section{Methods}

We collected data for the current study based on a purposeful sample of students who participated in a one-semester study abroad experience during the 2012 academic year. Of the 510 students who participated in the longitudinal study, approximately $50 \%$ of the sample was selected from eleven college campuses (38\% private and $12 \%$ public) and $50 \%$ was selected from two study abroad third-party providers. Participating students completed the general and study abroad forms of the Global Perspective Inventory (GPI; Braskamp et al., 2013) via a web-based platform prior to their departure abroad and immediately upon re-entry after their semester long program. Both the general and study abroad forms of the GPI assess students' holistic development across cognitive, intrapersonal, and interpersonal dimensions. The general form of the GPI contains 76 questions, consisting of both the inventory and experiential questions that measure various forms of campus engagement prior to the study abroad experience. The study abroad form contains 73 questions, consisting of both the inventory and a number of process-based measures designed to tap into critical aspects of the study abroad experience, including students' assessment of their pre-departure experience, the influence of faculty and staff, their interactions with the host country, and their exposure to different pedagogical and classroom-based practices.

Of the 510 students who participated in the longitudinal survey, approximately $71 \%$ were female and $80 \%$ were White, with Students of Color representing 3\% Black, 5\% Hispanic, 3\% Asian, 6\% mixed race, and the remaining 3\% unknown. The sample also included sophomores $(12 \%)$, juniors (49\%), and seniors (39\%) who represented a variety of majors, including Arts and Humanities (19\%), Business and Law (21\%), Social and Behavioral Sciences (19\%), and smaller percentages (less than 10\%) in other major categories. Approximately $38 \%$ of the sample participated in an internationally-themed living-learning program prior to their study abroad departure, and 86\% indicated they had never studied abroad prior to the current semester. Finally, approximately $79 \%$ of the sample indicated that their parents' highest level of educational attainment was at the baccalaureate level or higher, 13\% indicated some college, and $9 \%$ indicated high school or less.

\section{Variables}

The dependent variables for the study represent the six scales of the GPI. The GPI scales measure cognitive knowing and knowledge (i.e., viewing knowledge and knowing with greater complexity and taking into account multiple cultural perspectives), intrapersonal identity and affect (i.e., becoming more self-aware of one's strengths, values, and personal characteristics and developing an openness, awareness, and sensitivity to cultural differences), and interpersonal interaction and social responsibility (i.e., a willingness to interact with persons with different social norms and cultural backgrounds and an increasing sense of personal and social responsibility; see Braskamp et al., 2013 for information on scale items and reliability). 
Table 1. Factor Loadings and Reliabilities for Study Abroad and Pre-Departure Scales ( $\mathrm{N}=510)$

Developmental Influence of Faculty and Staff $(\alpha=.812)$

The onsite staff abroad took a genuine interest in my development as a person.

My interactions with the faculty shaped the way I understand the host culture.

I developed a strong relationship with one or more of my faculty while studying abroad.

Intercultural Wonderment $(\alpha=.724)$

How often did you intentionally push yourself out of your comfort zone?

How often did you feel immersed in the culture of the host country?

How often did you on your own explore new habits and behaviors while studying abroad?

.713

How often did you interact with individuals from the host country outside of the classroom?

Pre-Departure Engagement in Current Events $(\alpha=.847)$

Followed an international event/crisis (e.g., through newspaper, social media, or other

media source)

Read a newspaper or news magazine (online or in print)

Watched news programs on television

Discussed current events with other students

Pre-Departure Engagement in Curriculum $(\alpha=.688)$

Course that includes opportunities for intensive dialogue among students with different

backgrounds and beliefs

Course focused on significant global/international issues and problems

Multicultural course addressing issues of race, ethnicity, gender, class, religion, or sexual

orientation

World history course

Pre-Departure Engagement in Co-Curriculum $(\alpha=.702)$

Participated in community service activities

Participated in leadership programs that stress collaboration and team work

Attended a lecture//workshop/campus discussion on international/global issues

Participated in events or activities sponsored by groups reflecting your own cultural heritage

In addition to the dependent variables, we included controls for student background characteristics (i.e., gender, race, and parent educational attainment) and pre-departure characteristics (i.e., class standing and college grade point average). The student background variables were transformed into dummy variables, with males, White students, and parent educational attainment at the baccalaureate level or higher serving as referent groups, respectively. Similarly, students' class standing was transformed into a set of three dummy variables, with seniors serving as the referent group. Finally, college grade point average was measured on a standard, continuous four-point scale. 


\section{Mark E. Engberg \& T.J. Jourian}

We also included a number of pre-departure engagement variables, including previous study abroad experiences; whether the student participated in an international/global living learning program; pre-departure engagement in the curriculum, co-curriculum, and current events; and the usefulness of the pre-departure orientation. Students' previous exposure to study abroad was transformed into a set of four dummy variables, representing no study abroad, a short-term study abroad experience, one semester of study abroad, and more than one term, with no previous study abroad serving as the referent group. Students' participation in an international/global living learning program was a dichotomous variable indicating whether or not they had lived in a program prior to studying abroad. The pre-departure engagement scales were derived through factor analysis with reliabilities ranging from .847 to .688 (see Table 1 for information on item wording, loadings, and reliabilities). The current events scale consisted of four items that measured the extent to which students followed an international crisis, read a newspaper or magazine, watched a news program, or discussed current events with other students. The curriculum scale included four items that examined the number of courses that students took prior to studying abroad, including diversity-based courses and courses with an international/global focus. The co-curricular scale consisted of five items that measured how often students were engaged in community service, leadership programs, and events related to international/global issues and different cultural groups on campus. Finally, we included a continuous measure that examined students' level of agreement about the usefulness of their predeparture orientation in preparing them for their time abroad.

In addition to pre-departure measures, we included a number of process-related variables that examined students' engagement with the study abroad curriculum, co-curriculum, and community, including intercultural wonderment, the developmental influence of faculty and staff, classroombased assignments involving the community and reflective activities, and the extent to which students discussed/shared their experience with others. The intercultural wonderment scale contains four items that represent how often students pushed themselves outside of their comfort zone, felt immersed in the host country, explored new habits and behaviors, and interacted with members of the host country outside of the classroom (Alpha $=.724)$. The developmental influence of faculty and staff was a three-item factor that examined the extent to which staff took an interest in students' development, whether faculty shaped their understanding of the host culture, and whether they developed a strong relationship with faculty during their study abroad (see Table 1 for item wording, loadings, and reliability). The four additional measures of student engagement abroad were all continuous measures in which students indicated how often they spoke the host language inside/outside the classroom (average of two items), shared/discussed their study abroad experience with others, and the extent to which their classroom assignments involved gathering information from the surrounding community or reflective-based activities.

\section{Analysis}

Prior to addressing the three research questions, we first performed a number of data conditioning steps, including a missing data analysis (under $1 \%$ for the sample), data transformations, and factor analysis. In relation to the factor analytic procedures, we conducted an orthogonal principal components analysis on the experiential questions contained in both the general 
and study abroad forms of the GPI using a Varimax rotation. All item loadings were above .40 and factor reliabilities ranged from a low of .688 to a high of .847 .

In examining the three research questions of the study, we first ran a set of paired sample t-tests across each of the pretest and posttest GPI outcomes measures and calculated the associated effect sizes of the change. Next, we ran two sets of hierarchical, ordinary least squares (OLS) multiple regressions: in the first set, we regressed the six GPI scales on the independent variables described above, including an associated pretest measure and the intercultural wonderment scale; in the second set, we regressed the intercultural wonderment scale on the four sets of independent variables. All results are presented using unstandardized beta coefficients $(B)$, in order to allow comparisons across models.

\section{Limitations}

There are several limitations in the current study. First, we relied on a purposeful sample of students that was gathered directly from participating colleges along with two third-party study abroad providers. In doing so, we recognize there are limitations to the external validity of the results and some caution is necessary in extrapolating these results beyond the sampled population. We did, however, employ a longitudinal design with college impact controls related to both student inputs and a number of environmental variables that have been shown to be important influences on study abroad outcomes. Additionally, we recognize that there may be additional controls and contextual influences that we were not able to capture in this study. In any given survey there are limits to the number of questions one can ask of students, and we were intentional in selecting questions that were both grounded in the literature and emphasized by many of the practitioners of study abroad whom we consulted in creating the survey items. Finally, we also recognize some of the inherent limitations of self-report instruments and plan to extend the current study to incorporate additional qualitative information to better understand the range of factors that are important in inducing intercultural wonderment.

\section{Results}

In examining the first research question of the study, we found significant and positive preposttest change on all of the GPI scales (see Table 2). The largest effects were found on the Knowledge and Identity scales (Cohen's $D=.56$ and .40 respectively, whereas the smallest effects were found on the Knowing, Interaction and Social Responsibility scales (Cohen's $D=.22$, .23. and .23, respectively).

In examining the OLS regression models predicting change in the GPI scales, the adjusted rsquare values ranged from high values of .497 and .443 for the Social Responsibility and Social Interaction models, respectively, to lows of .283 and .285 for the Knowledge and Affect models, respectively. In relation to the Intercultural Wonderment scale, we found significant effects across each of the six models (see Table 3$)$. The largest effect was found on the Social Interaction scale $(B=$ $.277, p<.001)$ followed by the Knowing $(B=.158, p<.001$ and Knowledge scales $(B=.134, p<$ 
Table 2. Paired Samples T-Tests across GPI Domains $(n=510)$

\begin{tabular}{|c|c|c|c|c|c|}
\hline & \multicolumn{2}{|c|}{ Mean Values } & \multicolumn{3}{|r|}{ Effect size } \\
\hline & Time 1 & Time 2 & Diff & & Cohen's D \\
\hline Knowing & 3.78 & 3.88 & 0.10 & *** & 0.22 \\
\hline Knowledge & 3.55 & 3.86 & 0.31 & $\star \star \star *$ & 0.56 \\
\hline Identity & 3.97 & 4.14 & 0.17 & $* \star *$ & 0.40 \\
\hline Affect & 4.11 & 4.23 & 0.12 & $* * *$ & 0.29 \\
\hline Interaction & 2.80 & 2.94 & 0.14 & $* \star *$ & 0.23 \\
\hline Social Responsibility & 3.73 & 3.83 & 0.10 & $\star * *$ & 0.23 \\
\hline
\end{tabular}

.001 for both outcomes); the smallest effect was associated with the Identity scale $(B=.085, p<.01)$ followed by the Social Responsibility scale $(B=.106, p<.01)$. Thus, as student's level of intercultural wonderment increases, there is a concomitant increase in their development of a global perspective, particularly in relation to their proclivities toward intercultural interaction and how they make meaning of intercultural experiences.

In addition to the consistent effects uncovered for the Intercultural Wonderment scale, we found significant effects for each of the pretest outcome measures, with the largest effect found on the Social Responsibility scale $(B=.554, p<.001)$ and the smallest effect on the Knowledge scale $(B=.362, p<$ .001). In examining less consistent effects across models, we noted a significant, negative effect for White students in the Interaction model $(B=-.272, p<.001)$, demonstrating that White students scored significantly lower than students of color, controlling for other effects in the model. We also uncovered a significant, positive effect in relation to parents with some college on the Knowing model $(B=.182, p<.001)$ compared to parents with a baccalaureate degree or higher.

In terms of pre-departure characteristics, we found significant effects for college grade point average on the Affect $(B=.082, p<.05)$, Social Interaction $(B=.126, p<.05)$, and Knowing models $(B=.099, p<.05)$, demonstrating that higher grade point averages in college are associated with higher scores in the cognitive, intrapersonal, and interpersonal domains. In examining pre-departure forms of engagement, we found a significant, positive effect for students who lived in an international/global themed residence hall on the Knowledge $(B=.105, p<.01)$ and Social Responsibility scales $(B=.076, p<.05)$. Additionally, we uncovered contrasting effects in relation to students' involvement in current events, with negative effects found on the Knowing scale $(B=-.056$, $p<.05)$ and positive effects found on the Knowledge scales $(B=.092, p<.001)$. We also noted a significant, positive effect in relation to the usefulness of the pre-departure orientation on the Identity scale $(B=.034, p<.05)$. Finally, in relation to study abroad-based experiences, we found significant, positive effects for students who shared/discussed their study abroad experiences with others on the Identity $(B=.062, p<.01)$, Affect $(B=.066, p<.001)$, and Responsibility scales $(B=.073, p<.01)$. 
Table 3: OLS Regression Predicting GPI Outcomes based on Study Abroad Experience ( $\mathrm{N}=510)$

\begin{tabular}{|c|c|c|c|c|c|c|}
\hline 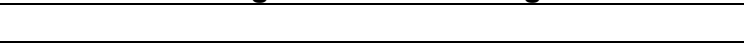 & Knowing & Knowledge & Identity & Affect & Interact & Response \\
\hline & $\mathrm{B}$ & $\mathrm{B}$ & $\mathrm{B}$ & $\mathrm{B}$ & $\mathrm{B}$ & $\mathrm{B}$ \\
\hline \multicolumn{7}{|l|}{ Student Background Characteristics } \\
\hline Female & .071 & .068 & .053 & .046 & .039 & .078 \\
\hline White & .012 & .065 & .041 & .004 & $-.272^{\star \star \star}$ & -.065 \\
\hline High School or Less (BA or higher) & .087 & .076 & -.044 & .107 & .106 & -.042 \\
\hline Some College (BA or higher) & $.182^{\star \star \star}$ & .035 & -.038 & .086 & .138 & .050 \\
\hline \multicolumn{7}{|l|}{ Pre-Departure Characteristics } \\
\hline Sophomore (Senior) & .044 & .062 & -.098 & -.043 & -.053 & -.001 \\
\hline Junior (Senior) & .003 & .033 & -.038 & .031 & -.023 & .030 \\
\hline College Grade Point Average & $.099 *$ & .015 & -.025 & $.082^{*}$ & $.126^{\star}$ & .042 \\
\hline \multicolumn{7}{|l|}{ Pre-Departure Engagement } \\
\hline Previous Study Abroad--Short Term (none) & .032 & -.020 & .061 & .048 & .020 & .073 \\
\hline Previous Study Abroad--One Term (none) & -.046 & .002 & .040 & -.001 & -.106 & -.102 \\
\hline Previous Study Abroad--More One Term (none) & .054 & -.007 & -.021 & -.108 & -.226 & -.206 \\
\hline $\begin{array}{l}\text { Participated in Int'//Global Living Learning } \\
\text { Program }\end{array}$ & .021 & $.105^{\star \star}$ & .064 & .028 & -.027 & $.076^{\star}$ \\
\hline Pre-departure Engagement in Current Events & $-.056^{\star}$ & $.092^{\star \star \star}$ & .038 & -.005 & .023 & .001 \\
\hline Pre-departure Engagement in Curriculum & .019 & .008 & .000 & .015 & .019 & .020 \\
\hline Pre-departure Engagement in Co-Curriculum & -.017 & .003 & -.007 & .006 & -.063 & .036 \\
\hline Usefulness of Pre-departure Orientation & .017 & .009 & $.034^{*}$ & .004 & .008 & .032 \\
\hline $\begin{array}{l}\text { Pretest Measure } \\
\text { Study Abroad Curricular, Co-Curricular and } \\
\text { Community Experiences }\end{array}$ & $.554^{\star \star \star}$ & $.362^{\star * *}$ & $.493^{\star \star \star}$ & $.377^{\star \star \star}$ & $.517^{\star \star \star}$ & $.621^{\star \star *}$ \\
\hline Developmental Influence of Faculty and Staff & .006 & $.049 *$ & -.007 & .003 & .006 & -.017 \\
\hline $\begin{array}{l}\text { Spoke Host Language Inside and Outside of } \\
\text { Classroom }\end{array}$ & -.012 & -.016 & -.018 & -.022 & .010 & -.012 \\
\hline Class Assignments Involved Community & .014 & .001 & .005 & .021 & $.055^{\star}$ & .023 \\
\hline Classroom-based Reflective Activities & -.027 & .023 & .021 & .015 & .020 & .001 \\
\hline Shared/Discussed Experience with Others & .019 & -.004 & $.062^{\star *}$ & $.066^{\star \star}$ & -.033 & $.073^{\star *}$ \\
\hline Intercultural Wonderment & $.158^{\star \star \star}$ & $.134^{\star \star \star}$ & $.085^{\star \star}$ & $.126 * \star \star$ & $.277^{\star \star \star}$ & $.106^{\star \star}$ \\
\hline
\end{tabular}




\section{Mark E. Engberg \& T.J. Jourian}

In relation to the final OLS regression model (see Table 4), in which we regressed the Intercultural Wonderment scale on the four sets of independent variables, we found several interesting effects. First, unlike the full regression model predicting the GPI scales, all of the study abroad curricular, co-curricular, and community experiences were significant predictors of Intercultural Wonderment. The largest effects were found in relation to students who shared/discussed their study abroad experiences with others $(b=.221, p<.001)$, the developmental influence of faculty and staff $(b=.153, p<.001)$, and speaking the host language inside/outside the classroom $(b=.131, p<.001)$, whereas the smallest effects were related to class assignments that involved either reflective activities $(b=.114, p<.01)$ or community engagement $(b=.128, p<.01)$. Second, we uncovered a significant, positive effect for students who reported living in an international/global living-learning program $(b=.114, p<.01)$, as well as for those who reported a higher level of pre-departure engagement in the co-curriculum $(b=.092, p<.05)$. Thus, intentionally designing study abroad experiences with attention to faculty/staff support and challenge, curricularbased activities designed to engage the community and reflect on one's experience, speaking the host language, and sharing and discussing one's experience with others are all important catalysts in fostering higher degrees of intercultural wonderment.

Table 4: OLS Regression Predicting Intercultural Wonderment in Study Abroad Experiences ( $N=510)$

\begin{tabular}{|c|c|c|c|c|}
\hline & B & SE & beta & \\
\hline \multicolumn{5}{|l|}{ Student Background Characteristics } \\
\hline Female & -.052 & .055 & -.040 & \\
\hline White & -.021 & .061 & -.014 & \\
\hline High School or Less (BA or higher) & .173 & .089 & .081 & \\
\hline Some College (BA or higher) & .061 & .072 & .034 & \\
\hline \multicolumn{5}{|l|}{ Pre-Departure Characteristics } \\
\hline Sophomore (Senior) & -.070 & .084 & -.038 & \\
\hline Junior (Senior) & -.030 & .053 & -.026 & \\
\hline College Grade Point Average & -.009 & .061 & -.006 & \\
\hline \multicolumn{5}{|l|}{ Pre-Departure Engagement } \\
\hline Previous Study Abroad--Short Term (none) & -033 & .077 & -.018 & \\
\hline Previous Study Abroad--One Term (none) & .181 & .170 & .045 & \\
\hline Previous Study Abroad--More One Term (none) & -.462 & .269 & -.069 & \\
\hline Int'//Global Living Learning Program & .138 & .050 & .114 & ** \\
\hline Pre-departure Engagement in Current Events & .026 & .030 & .037 & \\
\hline Pre-departure Engagement in Curriculum & -.008 & .027 & -.013 & \\
\hline Pre-departure Engagement in Co-Curriculum & .073 & .035 & .092 & * \\
\hline Usefulness of Pre-departure Orientation & .004 & .025 & .008 & \\
\hline \multicolumn{5}{|c|}{$\begin{array}{l}\text { Study Abroad Curricular, Co-Curricular and Community } \\
\text { Experiences }\end{array}$} \\
\hline Developmental Influence of Faculty and Staff & .100 & .030 & 153 & *** \\
\hline Spoke Host Language Inside/Outside Classroom & .062 & .019 & .131 & *** \\
\hline Class Assignments Involved Community & .074 & .026 & .128 & ** \\
\hline Classroom-based Reflective Activities & .052 & .020 & 114 & ** \\
\hline Shared/Discussed Experience with Others & .185 & .035 & .221 & $\star \star \star *$ \\
\hline
\end{tabular}

$* \mathrm{p}<.05 ; * * \mathrm{p}<.01 ; * * * \mathrm{p}<.001$ 


\section{Discussion}

Numerous studies have demonstrated the potential of study abroad experiences to influence students' development of intercultural and global learning outcomes (Engberg, 2013.; Salisbury et al., 2013). Yet, many of these studies fail to adequately examine how different programmatic and support elements contribute to students' learning, leaving many unanswered questions in relation to how immersion experiences can be used to optimize global education missions on many college campuses today. Researchers have also called into question the ubiquity of study abroad experiences in achieving learning outcomes for all students (Twombly et al., 2012), as well as the notion that immersion in a foreign country is sufficient in and of itself in achieving intercultural outcomes (Vande Berg, Paige, \& Lou, 2012). Stearns (2009) suggests that study abroad programs should be regularly assessed and that administrators should routinely examine existing problems and next steps needed to improve the efficacy of such programs. In this study, we address these calls to more adequately assess the features of an immersion experience that contribute most to students' development of a global perspective. In doing so, we introduce a new concept, intercultural wonderment, as a means of better understanding how students' mindfulness, curiosity, personal investment, and active experimentation in study abroad settings can create the necessary conditions to disrupt and enlarge familiar patterns of thinking and foster global learning and development.

We began our study by first examining the extent to which students change over the course of a one semester study abroad experience in relation to the developmental domains of the GPI. The results demonstrated that students significantly increased their GPI scores across cognitive, intrapersonal, and interpersonal dimensions, with the largest changes found in relation to the acquisition of cultural knowledge and students' emerging sense of self; these results are consistent with earlier studies examining global learning in relation to study abroad (Engberg, 2013).

Having established that students demonstrate significant change across the GPI outcomes over time, we next examined how a number of pre-departure and study abroad experiences influenced each of the GPI outcomes, with a particular emphasis on the role of intercultural wonderment. The results demonstrated that intercultural wonderment is an important determinant of change in students' global perspective, even when controlling for a number of competing curricular, cocurricular, and community-based experiences. In fact, with few exceptions, intercultural wonderment was the only consistent direct effect across each of the cognitive, intrapersonal, and interpersonal domains that makeup the GPI. Intercultural wonderment was particularly significant in developing students' proclivity to interact across cultural differences and their degree of complexity in contextualizing culture when acquiring and valuing knowledge. The consistent effects of intercultural wonderment suggest that students' natural curiosity to explore novel opportunities in the host country can create the necessary disequilibrium to disrupt automatic thinking patterns (Langer, 1978) and enlarge and recalibrate existing cognitive schema (Piaget, 1985), thereby promoting the global learning and developmental outcomes found in this study. 


\section{Mark E. Engberg \& T.J. Jourian}

In addition to examining the predictive qualities of intercultural wonderment, we sought to understand the extent to which different aspects of the programmatic context abroad (i.e., varying curricular, co-curricular, and community based study abroad experiences) were significantly related to intercultural wonderment. While many scholars have touted the importance of these design features (Jessup-Anger, 2008; Jones et al., 2012; Knight \& Schmidt-Rinehart, 2010; Lee, 2012; Savicki \& Cooley, 2011; Vande Berg, et al., 2009), these practices have not been specifically linked to the intercultural wonderment construct. The results demonstrated that in all cases, these contextual experiences inside and outside the classroom were significantly related to students' level of intercultural wonderment. Thus, the results suggest that intercultural wonderment is induced through the intentional design of study abroad experiences that involve faculty and staff support, classroom-based opportunities to reflect and engage with the host community, and formal and informal opportunities to speak the host culture's language and share and discuss one's experience with others. While not specifically examined in this study, the results suggest that many of the intentionally designed features of a study abroad experience may indirectly influence the development of a global perspective by increasing students' active experimentation and curiosity to explore new habits, behaviors, and individuals that are less familiar and lie outside of their comfort zone.

\section{Implications}

There are a number of implications from this study that will likely benefit those interested in the administration of study abroad experiences, experiential pedagogy, and interactions across difference. These implications touch on the design and facilitation of study abroad programs, as well as the importance of taking the campus and host community contexts into consideration. Additionally, as this study has introduced intercultural wonderment to the study abroad literature, it opens up new avenues for future research and inquiry.

\section{Study Abroad Design}

It has been suggested that simply immersing students in a foreign country, while a necessary condition, is insufficient in realizing the full level of benefits that can accrue from a cross-cultural experience, such as a semester abroad (Vande Berg et al, 2012). Students need to be placed in environments that intentionally structure opportunities for cross-cultural interaction and active exploration of the host country while concomitantly providing them with opportunities for reflective learning. Effective programmatic design needs to incorporate curricular, co-curricular and community-based experiences that both challenge and support students to step outside of their comfort zones and immerse themselves more intentionally in the host country. Structured and unstructured opportunities should be offered both inside and outside of the classroom for students to use the host country's language, ideally with native speakers from the host country. Additionally, students need opportunities for both guided reflection and more informal opportunities to discuss their study abroad experiences with others.

Students need to develop an active and curious disposition when exploring and appreciating new

cultural opportunities, and this is nourished, in part, by faculty and staff who both support and 
challenge students to push themselves out of their comfort zones and explore the new culture. To accomplish this goal, faculty and staff need to be provided with training, tools, and knowledge to appropriately assess students' developmental needs and determine what is needed to further their growth in multiculturally and interculturally competent ways. Pedagogical tools, such as intergroup dialogue facilitation (Zúñiga, Nagda, Chesler, \& Cytron-Walker, 2007), may also prove useful within the classroom.

\section{Campus-wide Pre-Departure and Environment}

Study abroad programs are not designed in a vacuum, but rather occur within the context of a campus environment and community. University administrators who wish to see more students not only taking advantage of study abroad opportunities but also pushing themselves outside their comfort zones when participating in these programs, should also examine whether the campus as a whole encourages this practice and in what type of settings. Classes that intentionally push students to examine and explore their beliefs and values from multiple perspectives may be important antecedents in fostering later desires to explore new habits and behaviors while studying abroad. Opportunities to interact with diverse others in purposeful ways in the residence halls (such as in international/global/diversity themed halls), in student activities and organizations, and in the classroom may also provide students with the skills and confidence to seek out additional interactions across difference when studying abroad. In particular, an affirming and positive climate for marginalized students is a basic and necessary element in creating an environment that makes it safe for all students to challenge themselves and become immersed in the campus culture.

\section{Future Research and Inquiry}

Further research is needed that explores the full range of design and process elements that induce intercultural wonderment while recognizing the importance of examining direct, indirect, and mediating effects. There is a need for additional inquiry in relation to how one's identity influences one's study abroad experience, and whether identity moderates the impact of intercultural wonderment on the development of student learning outcomes. Additionally, there is a dearth of research that examines how the diversity of the host community and resultant attitudes in relation to race, gender, and the United States might impact students' intercultural wonderment or other study abroad outcomes. Further, as a new feature of study abroad research, intercultural wonderment is conducive to additional study, particularly qualitative inquiry that can better understand how students make meaning of their study abroad experience and develop a naturalistic wonder around cultural immersion. Regardless of the outcome under question, this study addressed the need to examine more closely the processes that optimize study abroad learning and improve the likelihood that all students will benefit from their limited time immersed in a new culture. 


\section{Mark E. Engberg \& T.J. Jourian}

\section{References}

Association of American Colleges and Universities. (2007). College learning for the new global century: A report from the National Leadership Council for Liberal Education and America's Promise. Washington, DC: Association of American Colleges and Universities

Astin, A. (1977). Four critical years: Effects of college on beliefs, attitudes, and knowledge. San Francisco: Jossey-Bass.

Baxter Magolda, M. B. (2001). Making their own way: Narratives for transforming higher education to promote self-development. Sterling, VA: Stylus.

Baxter Magolda, M.B. (2008). Three elements of self-authorship. Journal of College Student Development, 48, 491-508.

Bennett, M. (1993). Towards ethnorelativism: A development model of intercultural sensitivity. In M. Paige (Ed.), Education for the intercultural experience (pp. 21-71). Yarmouth, ME: Intercultural Press.

Braskamp, L.A. (2009). Applying personal investment theory to better understand student development. In A. Kaplan, S.A. Karabenick, \& E. De Groot (Eds.), Culture, self, and motivation: Essays in honor of Martin L. Maehr (pp. 21-38). Charlotte, NC: Information Age Publishing.

Braskamp, L.A., Braskamp, D. C. \& Engberg, M.E. (2013). Global Perspective Inventory. Retrieved from https://gpi.central.edu/supportDocs/manual.pdf

Braskamp, L. A., \& Engberg, M. E. (2011). How colleges can influence the development of a global perspective. Liberal Education, 97, 34-39.

Braskamp, L. A., Trautvetter, L. C. \& K. Ward. (2006). Putting students first: How colleges develop students purposefully. Bolton, MA: Anker.

Chickering, A.W. \& Reisser, L. (1993). Education and identity (2 ${ }^{\text {nd }}$ ed.). San Francisco, CA: JosseyBass.

Coryell, J. E. (September 06, 2011). The Foreign City as Classroom: Adult Learning in Study Abroad. Adult Learning, 22, 3, 4-11.

Engberg, M. E. (2013). The influence of study away experiences on global perspective-taking. Journal of College Student Development, 54(5), 466-480.

Gurin, P., Dey, E.L., Hurtado, S., and Gurin, G. (2002). Diversity and Higher Education: Theory and Impact on Educational Outcomes. Harvard Educational Review, 72(3), pp. 330-366.

Jessup-Anger, J. E. (2008). Gender Observations and Study Abroad: How Students Reconcile CrossCultural Differences Related to Gender. Journal of College Student Development, 49, 4, 360 373.

Jones, S.R., Rowan-Kenyon, H.T., Ireland, S.M., Niehaus, E. (2012). The meaning students make as participants in short-term immersion programs. Journal of College Student Development, 53(2), pp. 201-220.

Kegan, R. (1994). In over our heads: The mental demands of modern life. Cambridge, MA: Harvard University Press.

King, P.M., \& Baxter Magolda, M.B. (2005). A developmental model of intercultural maturity. Journal of College Student Development, 46(6), pp. 571-592.

Kolb, D.A. (1984). Experiential Learning experience as a source of learning and development. New Jersey: Prentice Hall. 
Knight, S. M., \& Schmidt-Rinehart, B. C. (June 06, 2010). Exploring Conditions to Enhance Student/Host Family Interaction Abroad. Foreign Language Annals, 43, 1, 64-79.

Kuh, G. D. (2003). What we're learning about student engagement from NSSE: Benchmarks for effective educational practices. Change, 35(2), pp. 24-32.

Langer, E.J. (1978). Rethinking the role of thought in social interaction. In J. Harvey, W. Ickes, \& R. Kiss (Eds.), New directions in attribution research (Vol. 3, pp. 35-38). Hillsdale, NJ: Erlbaum.

Lee, L. (2012). Engaging study abroad students in intercultural learning through blogging and ethnographic interviews. Foreign Language Annals, 45(1), 7-21.

Lewis, R., Davis Lenski, S., Mukhopadhyay, S., \& Cartwright, C.T. (2010). Mindful wonderment: Using focus groups to frame social justice. Journal for Social Action in Counseling and Psychology, 2(2), pp. 82-105.

Love, P.G. \& Guthrie, V.L. (Eds.). (1999). Understanding and applying cognitive development theory. New Directions for Student Services, No. 88. San Francisco, CA: Jossey-Bass.

Maehr, M. L., \& Braskamp, L. A. (1986). The motivation factor: A theory of persona investment. Lexington, MA: Heath \& Co.

Martinsen, R. (April 08, 2011). Predicting Changes in Cultural Sensitivity among Students of Spanish during Short-term Study Abroad. Hispania, 94, 1, 121-141.

Marx, H., \& Moss, D. M. (2011). Please Mind the Culture Gap: Intercultural Development during a Teacher Education Study Abroad Program. Journal of Teacher Education, 62, 1, 35-47.

Pascarella, E.T. \& Terenzini, P.T. (2005). How college affects students (Vol. 2): A third decade of research. San Francisco: Jossey-Bass.

Piaget, J. (1965). The moral judgment of the child. New York, NY: Free Press.

Piaget, J. (1985). The equilibrium of cognitive structures: The central problem of intellectual development. Chicago, IL: University of Chicago Press.

Pizzolato, J.E. (2005). Creating crossroads for self-authorship: Investigating the provocative moment. Journal of College Student Development, 44, 797-811.

Reisser, L. (1995). Revisiting the seven vectors. Journal of College Student Development, 36, 505-511.

Rexeisen, R. J., \& Al-Khatib, J. (January 01, 2009). Assurance of Learning and Study Abroad: A Case Study. Journal of Teaching in International Business, 20, 3, 192-207.

Salisbury, M.H., An, B.P., \& Pascarella, E.T. (2013). The effect of study abroad on intercultural competence among undergraduate college students. Journal of Student Affairs Research and Practice, 50(1), 1-20.

Sanford N. (1966). Self and society. New York, NY: Atherton Press.

Savicki, V., \& Cooley, E. (2011). American identity in study abroad students: Contrasts, changes, correlates. Journal of College Student Development, 52(3), 339-349.

Stearns, P.N. (2009). Educating global citizens in colleges and universities: Challenges and opportunities. New York, NY: Routledge.

Twombly, S. B., Salisbury, M. H., Tumanut, S. D., and Klute, P. (2012). Study abroad in a new global century: Renewing the promise, refining the purpose. San Francisco: Wiley/Jossey-Bass. Series: ASHE Higher Education Report, v. 38, no. 4.

Vande Berg, M., Connor-Linton, J., \& Paige, R. M. (2009). The Georgetown Consortium Project: Interventions for Student Learning Abroad. Frontiers: the Interdisciplinary Journal of Study Abroad, 18, 1-75. 


\section{Mark E. Engberg \& T.J. Jourian}

Vande Berg, M., Paige, R.M., \& Lou, K.H. (2012). Student learning abroad: What our students are learning, what they're not, and what we can do about it. Sterling, VA: Stylus Publications

Wielkiewicz, R.M. \& Turkowski, L.W. (2010). Reentry issues upon returning from study abroad programs. Journal of College Student Development, 51, 6, 649-664.

Zúñiga, X., Nagda, B. A., Chesler, M., \& Cytron-Walker, A. (2007). Intergroup dialogue in higher education: Meaningful learning about social justice. ASHE Higher Education Report, 32(4). San Francisco: Jossey-Bass. 